\title{
PRESENTACIÓN
}

\section{REINVENCIONES Y NUEVAS POÉTICAS DEL CINE \\ EN LA ERA POSINTERNET: SALIR DEL SCROLL. POR UNA MIRADA OFFLINE SOBRE LA IMAGEN DIGITAL}

DOI: https://doi.org/10.26439/contratexto2020.n034.4863

Cuando en el verano del 2019 redactamos el call for papers de este número de Contratexto, propusimos estudiar las transformaciones que nuestra relación con el cine y con la imagen ha sufrido a causa de "la democratización del acceso a internet, de las aplicaciones móviles, de las cámaras digitales y, en términos más generales, de las nuevas tecnologías y los nuevos medios audiovisuales". No podíamos imaginarnos entonces que, en los meses consecutivos, íbamos a ver cine únicamente en nuestras casas, que las filmotecas desplazarían su trabajo de programación y difusión a las redes (pensamos, por ejemplo, en la plataforma HENRI de la Cinémathèque francesa, que ha puesto a nuestra disposición, en línea, películas de vanguardia e incunables), que los rodajes se cancelarían, que el contacto con nuestros seres queridos quedaría confinado al espacio virtual; en definitiva, que viviríamos más que nunca en, por y a través de las pantallas. Hoy, tras la explosión de la pandemia de la covid-19, sentimos que las preguntas que nos hacíamos en aquel texto - ¿Qué implicaciones políticas conllevan estos cambios que está sufriendo el medio cinematográfico confrontado a internet?", escribimos entoncesson aún más relevantes y centrales si cabe. Nos complace, pues, contribuir a los debates que estos interrogantes suscitan con los ocho artículos que conforman este número.

El título del presente número de Contratexto menciona la "era posinternet" y nos parece importante detenernos un momento en este término, que no ha sido escogido a la ligera. Cuando hablamos del cine de la era posinternet, el prefijo pos-, como explica el artista Grégory Chatonsky, no comporta tanto una connotación diacrónica, sino una dimensión reflexiva y crítica respecto a internet, de la misma manera que la posmodernidad significó un giro, una reacción al fracaso del proyecto de la modernidad. No es que vivamos después de internet, todo lo contrario: es que vivimos tanto en internet, es que las redes median hasta tal punto nuestras existencias que el arte y el cine de nuestro tiempo no pueden ya eludir echar una mirada distanciada, offline, que alterna entre la sospecha, la fetichización y la ironía sobre internet. Se convierten así en "una inteligencia sensible capaz de dar marcha atrás" sobre las condiciones de posibilidad de las redes (Chatonsky, 2015). Esa inteligencia sensible que piensa las condiciones de posibilidad de internet es lo contrario de una inteligencia artificial. Se trata de la sensibilidad, la singularidad y la 
creatividad humanas de los artistas y cineastas cuyos trabajos son examinados en los artículos de esta revista. Si las obras artísticas aquí presentadas ponen de manifiesto la "maduración social de ciertas cuestiones artísticas" (Chatonsky, 2015) - sobre todo frente a la candidez naíf y fascinada del llamado net.art, cuyo nacimiento fue paralelo al desarrollo de internet-, lo hacen porque, como todo arte, retomando la célebre fórmula de Paul Klee, vuelve visible lo invisible, en este caso, concretamente, las arquitecturas internas y externas de internet $-y$ de sus diversas ramificaciones existenciales-, que "al infiltrarse en nuestras vidas en tantos niveles se vuelven casi invisibles" (Chatonsky, 2015). Las "reinvenciones" del cine que se comentan en este número de Contratexto funcionan, en ese sentido, como espejos cóncavos que nos muestran, bajo una nueva luz y con una aproximación reflexiva, imaginarios, discursos y representaciones singulares y específicos a nuestras existencias atravesadas por los medios y por el entrelazamiento, cada vez más íntimo, entre lo humano y lo tecnológico.

\section{(AN)ARCHIVOS, BASES DE DATOS E (IN)VISIBILIDAD}

Uno de los rasgos característicos de la posmodernidad, tal y como la definió el filósofo Fredric Jameson a finales de los años ochenta, es una especie de sordera histórica: la sociedad posmoderna está hipnotizada por "la contemplación aturdida, pero fascinada de un presente esquizofrénico" (Jameson, 2011, p. 19). La historia como relato teleológico basado en el mito del progreso ha perdido su valor articulador, socialmente aglutinante. En la lógica cultural del capitalismo tardío, se ha transformado en distracción superficial, en espectáculo. La tendencia posmoderna a la exaltación del presente como momento excepcional y de ruptura a menudo olvida, adoptando una actitud autorreferencial, establecer lazos con el pasado a fin de resaltar no únicamente las diferencias radicales, sino también continuidades y persistencias. Esa suerte de amnesia total del pasado, esa deriva presentista típica de nuestra época, coincide, desde los noventa, precisamente con el llamado archival turn (Simon, 2002) o archival impulse (Foster, 2004), el giro archivístico del arte contemporáneo que hace referencia al aumento, en las prácticas artísticas, de la explotación y exposición de archivos fotográficos, institucionales, científicos, entre otros, y de la (re)utilización de documentos y objetos históricos por parte de artistas, así como de la adopción de un cierto tipo de forma-archivo en la realización estética o conceptualización plástica de las obras. Esta coincidencia no es paradójica, sino que, al contrario, se podría apuntar a la angustia generada por la sordera histórica posmoderna como causa directa de ese giro archivístico adoptado por un arte preocupado por dotar a los discursos hegemónicos de una perspectiva histórica ausente. Además, en el giro archivístico también encontramos esa tendencia cultural al fragmento, a la apropiación y al remontaje, todos ellos elementos extremadamente posmodernos, junto a una cierta cultura estética de la información y del big data que explota también simultáneamente a finales del siglo xx. En las dos primeras décadas de nuestro siglo, esas tendencias 
que se apuntaban en los noventa han dado lugar a prácticas culturales ya totalmente generalizadas como "el remix, el sample o el mash up que ponen en cuestión nociones esenciales en la historiografía tradicional del arte y del cine, como autor, originalidad, propiedad intelectual, creatividad o innovación" (Hernández y Pena, 2019).

En el ámbito de la imagen en movimiento, uno de los grandes cambios producidos por la era posinternet es, en efecto, la disponibilidad y la accesibilidad de las imágenes, la multiplicación de bancos, de archivos de imágenes. El ejemplo más evidente son las plataformas de video en línea como YouTube, denominado por algunos teóricos como un "archivo accidental" (Burgess y Green, 2009) y por otros como un "anarchivo" (Ernst, 2012). Pero también el patrimonio cinematográfico, la herencia iconográfica, se ha abierto al gran público, por ejemplo, con la creación de archivos fílmicos virtuales institucionales como los examinados por Ignacio Albornoz Fariña en su artículo "Archivos fílmicos en línea: apuntes en torno al acervo universitario chileno" presente en este número. En efecto, la digitalización del mundo del capitalismo informacional conduce a la explosión de la producción, de la circulación y del almacenamiento de imágenes y datos, y, como bien exponen los artículos de este número, este fenómeno tiene consecuencias significativas e inevitables en el arte, la historia y la industria cinematográficos. En los años sesenta, Michel Foucault (1969/2009) definía el archivo como "el sistema que rige la aparición de los enunciados como acontecimientos singulares" (p. 170), es decir, la ley que determina lo que puede ser dicho 0 , en otras palabras, lo que limita y modela un determinado sistema epistemológico, lo que vincula el poder al conocimiento. El archivo es un espacio discursivo de control y gobierno; los gestos de archivar, guardar, recordar, implican necesariamente su reverso negativo: desechar, olvidar, la violencia ejercida por la jerarquización de la selección. Este ángulo de estudio nos lleva a considerar las implicaciones políticas de YouTube y, en general, de la totalidad de internet como depósito de la memoria humana, como espacio capaz de contener todo el saber de la humanidad, una suerte de biblioteca de Babel borgiana efectivamente realizada. Asimismo, permite comprender la importancia de un cuestionamiento y un reordenamiento de los archivos como labor discursiva, ideológica y ética, en lo cual insisten la mayoría de artículos de esta revista.

Sin embargo, YouTube y el resto de plataformas de alojamiento de video no son archivos, primero, porque su razón de ser no es la fijación, la conservación y la preservación - uno de los fundamentos del trabajo del archivista-, sino el incesante flujo de datos, la circulación y la transmisión acelerada, pues cuanto más circulan los videos entre los usuarios, más benficios generan, y más dinero ganan las empresas tecnológicas propietarias de las plataformas. De hecho, los contenidos de YouTube se caracterizan por su fragilidad e inestabilidad, pues a menudo son eliminados tanto por los usuarios que los han publicado como por la propia plataforma: "El nuevo archivo es radicalmente temporal, efímero y multimodal, correspondiendo a una cultura de usuario dinámica que se preocupa menos de los registros para la eternidad que del orden en la fluctuación" 
(Ernst, 2012, p. 6). En segundo lugar, internet no es un archivo porque está estructurado y ordenado según los metadatos elegidos por los creadores de contenidos y en la inteligencia artificial de los algoritmos de los motores de búsqueda. Es decir, al ser participativo, internet es un archivo que se autogenera, un "archivo generativo" (Ernst, 2012, p. 9). En ese sentido, si un archivo tiene un poder arcóntico (Derrida, 1997), que unifica, identifica y clasifica, este, en internet, serían los algoritmos, que no siguen una lógica de preservación basada en la identificación del valor de cada contenido y documento, la lógica del archivo. Así pues, como explica Snickars (2009), "el archivo digital es por naturaleza una base de datos" (p. 304). Para Lovink (2008), uno de los primeros teóricos en interesarse en la cultura participativa del giro 2.0 de internet, los utilizadores de este servicio practicamos "el arte de mirar bases de datos".

La capacidad de almacenamiento y las técnicas de indexación propios de internet traen consigo, aparentemente, una disponibilidad y una apertura democrática del saber humano y de la memoria visual de la humanidad, adoptando el formato de bases de datos abiertas al público. Sin embargo, el tamaño descomunal de estas bases de datos las vuelve incontrolables, ingobernables, de algún modo incomprensibles para el ser humano, que paradójicamente las ha creado. Internet es un hiperobjeto como el clima o el sistema solar: nos sobrepasa, no somos capaces de aprehenderlo. Los hiperobjetos "nos obligan a enfrentar algo que afecta nuestras ideas básicas sobre qué significa existir, qué es la Tierra, qué es la sociedad" (Morton, 2018, p. 38). 0 qué es el tiempo, qué es la historia, qué somos nosotros inscritos en ellos. Los hiperobjetos contienen ontológicamente esa potencia de honda interrogación existencial, de desplazamiento radical, de descentramiento del sistema de pensamiento antropocéntrico. Así, internet y su big data nos interrogan desde su no humanidad, desde su infinitud, desde su inconsciencia maquinal irreflexiva, involuntaria. Es precisamente esta no humanidad la que genera el doble digital al que se enfrenta el artículo "Reescrituras del género del terror desde las nuevas realidades digitales en Cam de Daniel Goldhaber" de Rodrigo Bedoya Forno. Si el historiador Pierre Nora consideraba que la inmediatez de los medios de masas y su tiempo real, "en vivo", vuelven el acontecimiento monstruoso porque trabajan contra la Historia, contra el trabajo del tiempo necesario al historiador, Marie Fraser sostiene que, a su vez, internet y la computación han transformado el archivo en algo monstruoso. El archivo-monstruo desvela que la hipervisibilidad implica invisibilidad, y la sobreinformación, desinformación, confusión: “¿No está al mismo tiempo sometiendo el conocimiento a la ininteligibilidad? [...] Frente a esta obsolescencia a la que está expuesto el archivo, ¿no deberíamos pensar en una memoria de la memoria, un archivo del archivo?" (Fraser, 2019, p. 185). En efecto, el archivo-monstruo, como hiperobjeto, necesita ser tratado, dividido, recortado, clasificado, archivado a su vez, para adaptarse a las medidas y a la psique humanas. Es necesaria una agentividad humana que, frente al archivo-monstruo de internet, aporte una reflexividad crítica, como apunta el artículo "El espectáculo, la cámara, la autoría y la vigilancia en el found footage" de Sergio José Aguilar Alcalá en 
su análisis de la importancia de la figura autoral en el cine de ficción que recrea las fórmulas del metraje encontrado. Es necesario un poder arcóntico no automatizado como los algoritmos, sino analítico, sensible, afectivo, estético, singular. Sin esa inteligencia creadora, sin esa subjetividad heterogénea y múltiple, será imposible construir una posición desde la cual llevar a cabo una interpretación crítica, por lo que internet será un lugar en silencio, pues, como nos recuerda Ernst (2012), "los documentos y las imágenes del archivo no hablan por sí solas" (p. 21). Es necesario hacerlas hablar.

En su artículo, Ignacio Albornoz Fariña insiste, retomando a Dominique Païni, en que una de las tareas esenciales del archivo como transmisor de saber es "la elaboración de una literatura sostén". Ese comentario, ese ejercicio de análisis y examen de los documentos, no es secundario o un mero apéndice a la tarea de conservación, sino que, bien al contrario, es una actividad central del archivo, imprescindible para darle sentido. Un archivo es inútil sin ella, pues de poco sirve "la felicidad engendrada por una copia perfectamente restaurada, si un punto de vista crítico [...] no impone el filme a la consciencia" (Païni, 1992, p. 45). Del mismo modo, el trabajo del cineasta alemán Harun Farocki con el found footage, comentado en el artículo de Camila Flores Fernández titulado "Cine de apropiación en los albores de la era digital: reflexiones a partir de la obra de Harun Farocki", o el del francés Romain Champalaune, analizado en el artículo de Allan Deneuville, “Óscar Pérez (1981-2018): crónica de una muerte anunciada”, demuestran el valor de la apropiación, del remontaje - "montaje controlado" decía Farocki-, de la relectura de documentos, de la rearticulación alegórica de los fragmentos del archivo para hacer hablar a las imágenes y para generar ese archivo del archivo-monstruo, esa memoria de la memoria de la que habla Marie Fraser frente al hiperobjeto de internet. Como recuerda Deneuville, la imagen digital se caracteriza por su "apropiabilidad", ese "copia y pega" inmediato que facilita e incita a su metacomentario, a su détournement, a su reciclaje. La película de Champalaune se inscribe en esa línea de prácticas artísticas de remediación de imágenes:

[Estas], en un ecosistema virtual saturado de imágenes, [...] apuestan por una ecología de la imagen, basada en la transmedialidad, aprovechándose de la contaminación audiovisual de internet para, reciclando desechos digitales a los que les añaden, a través del montaje, significaciones, potencialidades y funciones ausentes en las imágenes originales, producir nuevas obras sin la necesidad de producir nuevas imágenes. (Hernández y Pena, 2019)

Apuntan también estas películas a una cierta crisis de la imaginación, una suerte de incapacidad creativa provocada por la saturación visual. Las imágenes circulan y se multiplican a un ritmo tal que ahogan cualquier posibilidad de que una nueva imagen surja en medio del flujo constante de información compartida a toda velocidad. En estos tres textos, la idea de la intertextualidad es pregnante: las interconexiones entre las imágenes de Farocki y Champalaune hacen eco a los tags, etiquetas e hiperlinks que vinculan los textos fílmicos contenidos en los archivos universitarios chilenos. La 
intertextualidad permite que, en la base de datos que es nuestra cultura contemporánea (virtual), toda imagen comente otra, que todo filme prolongue otro. En un sentido distinto, Núria Gómez Gabriel, en su artículo "Espectropolítica: imagen y hauntología en la cultura visual contemporánea", estudia objetos artísticos contemporáneos que tienen en común la tarea de desvelar la invisibilidad de lo visible, de explorar las fallas del archivo, de la memoria. La imagen como velo que tapa y oculta en vez de representar algo, la hauntología como la disciplina que estudia esas ausencias, también hablan de cómo es necesario dotar de espesor histórico a un presente habitado por fantasmas, reactivar y despertar la memoria iconográfica.

\section{EL SUEÑO DE LAS MÁQUINAS PRODUCE MONSTRUOS}

¿Fue internet alcanzada por un francotirador en Siria, un dron en Paquistán o una granada de gas lacrimógeno en Turquía? ¿Está postrada en un hospital de Port Said con una bala en la cabeza? ¿Se suicidó saltando por la ventana de un Centro para el Dominio de la Información? (Steyerl, 2018, p. 201)

Estas son las preguntas que se hace Hito Steyerl en Arte duty free (2018), y acaba concluyendo que "internet no está muerta. Está muerta en vida y está en todos lados" (p. 201). La multiplicación de pantallas, la digitalización del mundo y el big data ha provocado que internet se extienda más allá de sí mismo, hasta finalmente estar presente en la realidad material incluso cuando nos desconectamos, cuando intentamos refugiarnos en un espacio offline. A pesar de que una gran parte de la población mundial sigue sin tener acceso a internet, o bien decide no utilizarlo, también sus vidas han pasado a ser afectadas por la influencia directa de aquello que sucede en las redes.

El diagnóstico de Steyerl sobre la expansión de internet vendría aquí a converger con la Declaración Transhumanista, un texto escrito originalmente por un grupo de intelectuales de distintas nacionalidades y que se ha ido reescribiendo con el paso de los años. Este texto defiende que la humanidad se verá afectada inevitablemente por el desarrollo tecnológico futuro y que en este cambio se abrirá la posibilidad de "ampliar el potencial del ser humano, superando el envejecimiento, las limitaciones cognitivas, el sufrimiento innecesario o nuestro confinamiento en el planeta Tierra" (Baily et al., 1998). En esta línea, sin embargo, las tesis transhumanistas reconocen el grave riesgo que implican estas posiciones, particularmente en lo que se refiere al mal uso, a la corrupción de cualquier nueva tecnología, por lo que defienden una profunda investigación de cualquier posibilidad de cambio con el objetivo de reducir estos riesgos potenciales, así como la creación de foros de debate en los que se puedan desarrollar discusiones constructivas respecto a las posibilidades que abren los avances tecnológicos para crear así un orden social que reduzca los riesgos existenciales y asegure la preservación de la vida y el bienestar. No obstante, a pesar de esas expectativas tecnooptimistas, la posibilidad de un colapso, la amenaza de un "futuro muerto", sigue extremadamente 
presente en nuestras sociedades definidas por el "realismo capitalista" del que habla Núria Gómez Gabriel en su texto.

Las innovaciones tecnológicas llevan al cuerpo humano allá donde este no llegaba anteriormente, al mismo tiempo que crea el nuevo peligro al que apunta el artículo de Arturo Morales Campos titulado "Signos hegemónicos en el filme Ex-Maquina: robotización y control", esto es, que la tecnología llegue efectivamente más allá de las capacidades del cuerpo humano, pero dejando atrás a la humanidad en lugar de acompañarla. La evolución de los nuevos dispositivos otorga al ser humano una condición de cyborg que le permite acceso inmediato a cantidades de información imposibles de procesar para la mente, borrar fronteras físicas y conectar en cuestión de segundos con otras personas a miles de kilómetros de distancia o alterar la imagen de sí mismo por la que es percibido. Sin embargo, alerta Steyerl (2018), esta implantación absoluta de la tecnología sobre el cuerpo humano lo somete también a cualquier poder que intente apropiarse de las posibilidades de control, vigilancia y represión que ofrece: "Podríamos estar desconectados, pero esto no significaría que hubiésemos escapado [...]. La policía golpea tu puerta por una descarga, para arrestarte después de 'identificarte' en YouTube o en un circuito cerrado de televisión" (p. 202). En este sentido, el artículo de Camila Flores Fernández recalca la meticulosa disección de las imágenes técnicas automatizadas, características de nuestra era, realizada por Farocki en varios de sus documentales ensayísticos de apropiación, imágenes "registradas por cámaras de seguridad, cámaras térmicas, los sistemas de vigilancia con reconocimiento facial o la filmación con drones" (Hernández y Pena, 2019), que se integran en una concepción del "cine como aparato ideológico", según Flores. Estas imágenes, transformadas en epítomes de nuestro tiempo, se recuperan y se reconstruyen también como motivo visual en el cine de ficción de género, tal y como analiza Sergio José Aguilar Alcalá en su artículo sobre el cine de found footage.

Internet se ha convertido en un lugar en el que todo puede ser visto, incluso aquello que creemos fuera de la red, un lugar capaz de contener y archivar todas las formas previas, todos los medios que lo preceden. El archivo de internet se convierte en un archivo palimpséstico, quizá una película analógica que ha sido proyectada en una pantalla y refilmada entonces para ser convertida en un código de información digital que se muestra como un conjunto de píxeles; Ignacio Albornoz Fariña habla de "copias digitales palimpsésticas" y de "pixelización de las colecciones". Esta rápida circulación de las imágenes, imágenes que se suben a la red, se descargan, se comparten, se reformatean o se editan, termina por producir alteraciones que se manifiestan como pequeñas imperfecciones en la imagen, instantes en los que las imágenes se deforman, hacen visibles los píxeles que las integran, formando formas abstractas o incluso agujeros negros, vacíos en la imagen compuestos por los píxeles "muertos" que han dejado de realizar su función. Se hace presente aquí la condición monstruosa de la imagen digital, una imagen informe, figural, inestable, fluctuante, de cualidades múltiples y sujetas a 
variaciones constantes: la imagen digital apunta a los límites de la representación, de la reproductibilidad técnica de la realidad. Sobre este punto, el artículo de Camila Flores propone que la obra de Farocki consiste en "una constante exploración de las posibilidades y límites de la imagen [...], lo que escapa a la representación".

El artículo "Imagens pobres e a ostentação do pixel. Relações entre cinema e internet em Videofilia (e outras síndromes virais)" de Regiane Akemi Ishii presenta la película de Juan Daniel F. Molero como un ejemplo de la manera en la que el cine contemporáneo ha intentado representar esa condición multiforme de la imagen digital, creada, compartida y modificada por quienes antes ocupaban únicamente la posición pasiva del espectador, amateurs que se han convertido en creadores de contenido precisamente en tanto que consumidores. Los llamados prosumers - como el venezolano Óscar Pérez del artículo de Allan Deneuville, obsesionado por generar un lifestream virtual y narcisista de su (trágica) existencia- se exponen a un régimen que ya no solo es de vigilancia panóptica, sino de "sousveillance catóptrica", en el cual todos los utilizadores, heridos de voyerismo, son vigilados y vigilantes simultáneamente. No obstante, el reverso positivo de esta condición es que la multiplicación de puntos de vista complejiza lo real y abre la posibilidad de generar contranarrativas a los discursos hegemónicos, como también lo hizo Óscar Pérez a su manera.

Estos fenómenos vernáculos producen nuevas formas sensibles a las que ya habíamos apuntado en nuestro call for papers al señalar la puesta en valor de una estética impuesta por las condiciones materiales de la imagen digital de baja definición. Las nuevas imágenes pobres permiten desarrollar "propuestas que trabajan con el píxel como materia propia de la imagen digital y la pantalla como lienzo" (Hernández y Pena, 2019). Por otro lado, estos contenidos generados por los usuarios (CGU) articulan una nueva identidad en internet que, como analiza Rodrigo Bedoya Forno en su texto sobre Cam (2018) de Daniel Goldhaber, puede llegar a tomar vida propia, a escapar a nuestro control, dando lugar a un desdoblamiento, un doppelgänger digital que, en nuestras peores pesadillas, usurpa a lo real. En un sentido complementario, el artículo de Sergio José Aguilar Alcalá estudia los usos que ha hecho el cine de ficción del formato del found footage para investigar de qué modo las posibilidades de intervención sobre las imágenes que ofrecen los nuevos medios digitales permiten revelar lo monstruoso que de otro modo permanecería oculto. Finalmente, en su texto a partir de Ex-Maquina (2015), Arturo Morales Campos muestra la confrontación de un otro que ya no es una identidad digital que ha tomado vida propia, sino un más allá de las propuestas tecnooptimistas de biomejoramiento: la inteligencia artificial que ya no complementa al ser humano, sino que, aprendiendo a ser más humana, termina por superarlo y ocupar su lugar en el mundo.

Hablábamos en la convocatoria para este número de cómo la accesibilidad de los formatos digitales ha permitido la manipulación de las películas por espectadores que 
devienen en creadores, una vez que las herramientas adecuadas están a su disposición, con la posibilidad de intervenir directamente sobre las imágenes digitales, que ofrecían entonces como "materia prima para elaborar su propia crítica" (Hernández y Pena, 2019). Si algo podemos decir respecto al conjunto de artículos que conforman la selección final de este número, es que demuestran la urgencia del cine y del arte en pensar su propia naturaleza en el momento histórico actual. No se trata ya únicamente de la posibilidad de "pensar la imagen a través de la imagen misma", como nos planteábamos en un principio, sino de la presente necesidad del arte de cuestionar la ontología de la imagen digital gracias a la ruptura con la inercia del scroll, frente a la frenética expansión de internet, convertido ya del todo en nuestro medio de existencia. Y este imperativo ineluctable se debe a que los flujos acelerados de las redes saturan nuestro intelecto y nuestros sentidos hasta anularnos, hasta atemorizarnos, explotando nuestra energía cerebral a través de lo que el filósofo Franco Bifo Berardi ha llamado "hipercomplejidad la excesiva intensidad y velocidad de los estímulos informativos que afectan al cerebro" (Berardi, 2014). Si los nuevos medios a veces nos asustan es por su monstruosidad automatizada e imparable, por su capacidad de - haciendo sensible su omnipotencia, su invulnerabilidad tecnológica - subrayar, en negativo, los límites de nuestra especie. Escribe Núria Gómez Gabriel en este número que, si los fantasmas nos recuerdan que nada quiere morir, también los nuevos medios digitales apuntan directamente a nuestra propia finitud. De algún modo, los nuevos medios producen fantasmas: "Los medios de producción y reproducción de imágenes devuelven a los hombres como espectros, como cuerpos impropios teledirigidos en la lejanía. Es decir que los medios (médiums) ya no intermedian con fantasmas, ahora los fabrican". Mucho antes de nuestra era posinternet, el director franco-chileno Raúl Ruiz (1987) ya lo confesaba: "Tengo miedo de los fantasmas. [...] ¿Cómo no tener miedo de los fantasmas, sobre todo mecánicos? ¿Cómo no tener miedo cuando en la televisión se escucha la voz de quien acaba de morir?" (p. 100). Recuperamos, pues, sus palabras y las redoblamos con fuerza hoy, desde un presente que más que nunca se parece a una película de terror. Los fantasmas de internet nos fascinan, nos asedian, nos obsesionan: brindamos aquí estos ocho artículos como ocho tentativas de exorcismo.

Gala Hernández López Editora adjunta Universidad de París VIII, Francia

Alejandro Pena Morado Editor adjunto Universidad Pompeu Fabra, España 


\section{REFERENCIAS}

Baily, D., et al. (1998). Transhumanist Declaration. https://humanityplus.org/philosophy/ transhumanist-declaration/

Burgess, J., y Green, J. (2009). YouTube. Online video and participatory culture. Polity Press.

Chatonsky, G. (2015). Post-internet: époque, ontologie et stylistique. http://chatonsky.net/ post-internet-definition/

Derrida, J. (1997). Mal de archivo. Una impresión freudiana. Trotta.

Ernst, W. (2012). Aura and temporality. The insistence of the archive. MACBA.

Foster, H. (2004). An archival impulse. October, 110, 3-22.

Foucault, M. (2009). La arqueología del saber. Siglo xxı. (Trabajo publicado originalmente en 1969).

Fraser, M. (2019). L'archive-monstre: de l'ars memoria au big data. En J.-M. Dallet y B. Gervais (Dirs.), Architectures de mémoire, 150-165. Les presses du réel.

Hernández, G., y Pena, A. (2019). Contratexto, 34 (2020-2). Reinvenciones y nuevas poéticas del cine en la era post-internet [call for papers]. Revista Contratexto. https://revistas.ulima.edu.pe/index.php/contratexto/announcement

Jameson, F. (2011). Le postmodernisme ou la logique culturelle du capitalisme tardif. Beaux Arts de Paris.

Lovink, G. (2008). The art of watching databases. En G. Loving y S. Niederer (Eds.), Video Vortex Reader. Responses to YouTube (pp. 9-12). Institute of Network Cultures.

Morton, T. (2018). Hiperobjetos. Filosofía y ecología después del fin del mundo. Adriana Hidalgo editora.

Païni, D. (1992). Conserver, montrer: où l'on en craint pas d'édifier un musée pour le cinéma. Yellow Now.

Ruiz, R. (1987). Entrevista. En C. Buci-Glucksmann y F. Revault d'Allones (Eds.), Raoul Ruiz (pp. 100-118). Dis Voir.

Simon, C. (2002). Introduction: following the archival turn. Visual Resources, 18(2), 101-107.

Snickars, P. (2009). The archival cloud. En P. Snickars y P. Vonderau (Eds.), The YouTube reader (pp. 292-313). National Library of Sweden.

Steyerl, H. (2018). Arte duty free. Caja Negra. 